\section{SKZ Extends its Adhesive Services}

$T_{\text {in }}^{\text {h }}$ he SKZ plastics centre in Würzburg

in Germany has added a low-pressure plasma system and a $\mathrm{CO}_{2}$ laser to its range of machines in the field of adhesives. This allows it to provide a lowpressure plasma pre-treatment service for its customers, alongside existing surface activation methods for plastics (such as atmospheric-pressure plasma, corona and flame treatment). In addition to activating surfaces before bonding, the new Pico low-pressure plasma system from Diener electronic offers a range of options for cleaning and coating substrates, including etching and polymerisation processes.

The Speedy $100 \mathrm{CO}_{2}$ laser from Trotec Laser $\mathrm{GmbH}$, which has an output of 45 watts, can be used for a variety of purposes, such as increasing the specific surface area of a plastic substrate by means of partial ablation, fusion, precision cutting of adhesive tapes, films and panels, marking, and exposing fibres in fibre composites.

These two surface treatment systems will be used in public research and development projects and in development assignments for industrial customers. They add the finishing touches to the range of services available for the most commonly used physical surface treatment processes in the plastics industry.

The plastics centre also offers a range of destructive and non-destructive tests and a variety of solutions for thermal and adhesive bonding of polymers.

For further information, please visit: www.skz.de

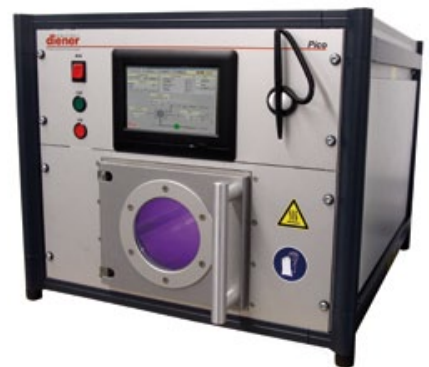

Low-pressure plasma system for cleaning, activation, etching and polymerisation processes.

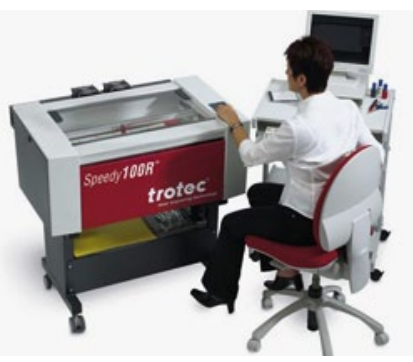

This $\mathrm{CO}_{2}$ laser can be used, for example, for increasing the specific surface area of a plastic substrate, for precision cutting of adhesive tapes, for marking purposes or for exposing fibres in fibre composites

\title{
Permit for New Large-Scale TDI Production Plant Granted
}

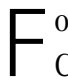
ollowing a detailed appraisal, the Cologne district authority has granted Bayer MaterialScience the permit to build and operate the new high-tech facility for the production of the chemical TDI (toluene diisocyanate) at Chempark Dormagen.

"We are delighted that the approval process has been successfully completed and we can press ahead with our construction work as planned," says Dr. Joachim Wolff, who is the member of Bayer MaterialScience's Executive Committee responsible for the Polyurethanes Business Unit. "This innovative hightech process marks the start of safe and eco-friendly world-scale polyurethane production that makes the best possible use of energy and resources. Compared with a conventional plant with the same capacity, the new facility will reduce energy consumption by up to 60 percent and require as much as 80 percent less solvent. This will also give us a decisive competitive edge."

The approval authorities gave the goahead for the provisional start of construction in February 2012. Since then, work at the giant construction site has been progressing in leaps and bounds. In November, for example, the construction team reached a key milestone when

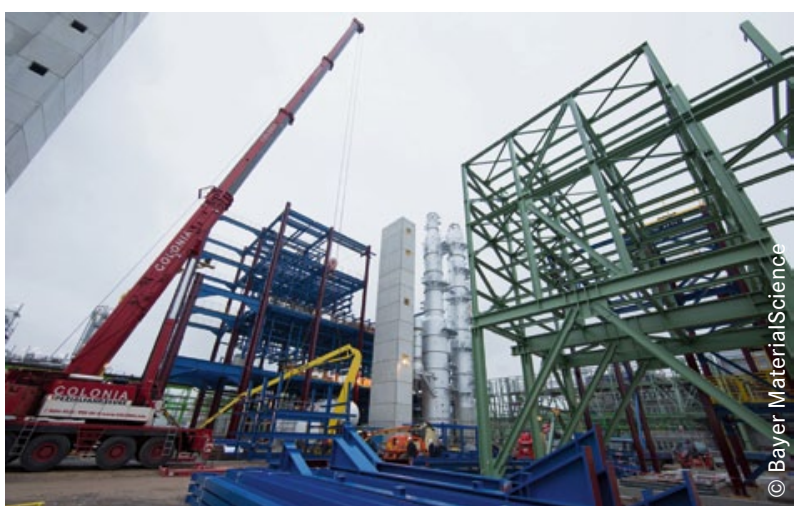

the TDI plant's 90.5 metric ton distillation column - a cylindrical steel structure - arrived at Chempark by truck.

With an annual capacity of 300,000 metric tons, the future world-scale plant is a key part of a long-term investment strategy at Bayer MaterialScience to turn its Dormagen site into a global technology centre for the development and production of polyurethanes.

The foundations have been laid ready for the building of the steel structure. Completion and start of operation of the new high-tech plant for the production of the chemical TDI (toluene diisocyanate) are planned for mid-2014. 